\title{
The Contribution of Structural Design to Green Building Rating Systems: An Industry Perspective and Comparison of Life Cycle Energy Considerations
}

\author{
Dane Miller ${ }^{a}$, Jeung-Hwan Doh ${ }^{b^{*}}$, Kriengsak Panuwatwanich ${ }^{\mathrm{c}}$, Niek van Oers ${ }^{\mathrm{d}}$ \\ ${ }^{a, b, c, d}$ Griffith School of Engineering, Griffith University, \\ Gold Coast Campus, Queensland 4222, Australia \\ *Corresponding author \\ E-mail address: J.doh@griffith.edu.au, Tel: +61 -7 555 29141, Fax: 61-7 55528065
}

\begin{abstract}
The construction industry provides extensive impacts to the environment with population increases further driving these pressures. In an attempt to mitigate these impacts, the industry as a whole has promoted and developed numerous green building rating systems (GBRS). These GBRS assign scores to buildings based on a variety of assessment criteria to determine a structures environmental impact. Previous research has identified shortfalls in certain areas related to these GBRS. In order to gain further insight into these systems an industry survey was conducted to establish an alternate perspective. The outcomes of this survey were consistent with that of previous research, identifying the requirement for an increase in the Embodied Energy (EE) consideration of structures in GBRS. The average estimation of the contribution of EE to a structures life cycle consumption was $28.4 \%$. The survey findings also identified a number of other key areas through which changes in the consideration of sustainable development could be improved. The use of these findings and their comparison to previous research outcomes would assist in the development of supplementary mechanisms to improve the assessment of the environmental performance of structures.
\end{abstract}

Keywords: Embodied Energy, Sustainable Development, Green Building Rating Systems, Building Life Cycle 
The construction, operation and maintenance of buildings have been extensively shown to have negative environmental impacts. These are said to account for between $40-50 \%$ of all energy usage and anthropogenic greenhouse gas (GHG) emissions globally [1-10]. The history and origins of the consideration of sustainability in the built environment is clearly and concisely presented by Lélé [11], Mebratu [12]. In addition to these, it has been reported that the operational contribution from buildings to total energy consumption in the United States, European Union and the United Kingdom are 40\%, 37\%, and $29 \%$ respectively $[13,14]$. In states that rely heavily on a service driven economy, for example Hong Kong, this proportion can be as high as $80 \%$ [15]. Waste generated by the building industry accounts for a significant proportion of landfill produced, with it being previously reported that in Australia, approximately $38 \%$ of waste generated originated from construction and demolition activities [16]. Similarly, in the Unites States, it is estimated that the building industry is responsible for producing $25-40 \%$ of total waste [17].

With Australia's population predicted to increase to approximately 35.5 million by the year 2056 [18], and global population estimated to hit 8.9 billion by 2050 [19], anthropogenic pressures driving construction rates will continue [20]. These pressures influence climate change and global warming with demand driving further environmental impacts associated with all relevant industry supply chains.

In Australia in order to keep pace with growing demand, approximately 30 million tonnes of finished building products are produced each year. Over $56 \%$ of this quantity, by mass, attributed to concrete and a further $6 \%$, steel [21]. In the US, each year, the development industry consumes over $40 \%$ of all raw stone, gravel and sand material, $25 \%$ of all raw 
timber, $40 \%$ of energy and $16 \%$ of water $[22,23]$. It is reported that globally, the production of cement alone causes between 5 and $7 \%$ of $\mathrm{CO}_{2}$ emissions due to consumption of fossil fuels $[24,25]$. These statistics highlight the potential benefits achievable by the entire construction industry, through any improved efficiency.

Notwithstanding the environmental impacts of the built environment, the construction industry provides significant contributions to the broad principles of Sustainable Development (SD) $[20,26]$. SD principles have been linked with the building industry, with many aspects appropriately considered. The building industry is referred to, as the lifeblood of the economy in the developed world [20] with its contribution to the economic dimension of SD being unquestioned. In the United States the construction industry is valued at over $\$ 1$ trillion and provides critical infrastructure to support industries while creating over 6.5 million jobs [23]. In Europe this industry provides the largest single contribution to employment with over $7.5 \%, 9.7 \%$ of the GDP and $47.6 \%$ of the gross fixed capital formation in 1999 [27], and these trends continue globally. Buildings are also shown to provide extensive social benefits including: good quality indoor living environments, structural integrity, safety for occupants, low vibration, high degree of weather protection, high fire resistance, good thermal resistance and sound acoustic performance [20, 28].

Traditionally, economic growth has been the key driving factor in building development [29]. The significant importance of buildings providing economic and social prosperity has consequently produced an inevitable side effect of a significant increase in energy consumption in the construction industry [30]. However, more recently, with the impacts of human activities on the environment becoming undeniable, sustainability has become an increasingly important topic across the industries stakeholders [20, 31, 32]. 
In partial response to the identification of the issues above, and related specifically to environmental impacts in the building industry, a number of mechanisms have been developed to assess the environmental performance of structures. Green Building Rating Systems (GBRS) assign scores to buildings based on a variety of assessment criteria including for example: potential savings in energy and water consumption, indoor environmental quality and the use of innovative materials. GBRS are becoming more prevalent globally with extensive variations existing [33]. The UK based Building Research Establishment's Environmental Assessment Method (BREEAM) has been previously identified as one of the world's pioneering rating systems [33]. Leadership in Environmental and Energy Design (LEED) and Greenstar, the most popular rating systems in the USA and Australia respectively, have adopted rating methodologies based partially on the mechanism introduced by BREEAM [33]. In each of the abovementioned rating systems, scores are assigned in a number of categories by meeting or exceeding benchmark criteria. The exact rating criteria as well as the scores available are dependent on building type, location and GBRS utilised. A final score is usually provided in terms of either a percentage or an ordinal qualitative descriptor (e.g. a number of 'stars'). The potential for these GBRS to effectively assess, and promote, sustainable development is well documented with numerous studies identifying their importance [34-38]. Conversely, issues with these assessment tools have been previously identified [8, 38] . Ding [38] noted that while there is no doubt that these assessment methods contribute to the goal of $\mathrm{SD}$, the current assessment systems have limitations in their effectiveness and usefulness. Ding [38] concluded that there is a requirement for greater collaborations across the building industry to promote and improve these existing assessment systems. It is anticipated that supplementary material is required to more suitably assess a buildings environmental performance. 
When considering environmental performance across any Building Life Cycle (BLC), there are two important phases to define: Embodied Energy (EE) and Operational Energy (OE). The total life cycle energy consumption of a building includes both of these phases $[8,39,40]$. It has been reported that the existing GBRS, tend to underestimate the role of EE in a typical BLC [17, 41]. A recent study by Miller and Doh [20] presents the variability estimated in published literature of the proportions of EE and OE in the BLC of typical concrete and steel framed structures. Despite this variability, it is widely accepted that EE and OE of approximately $20 \%$ and $80 \%$ respectively, when considering a typical BLC is common [41]. The average of the proportions of these phases, in the study conducted by Miller and Doh [20], was $18.6 \%$ EE in comparison to $81.4 \%$ OE. Notwithstanding these findings, investigations into the proportion of points being allocated to EE considerations in three main existing green building assessment systems are approximately $11 \%, 8 \%$ and $7 \%$ by BREEAM, LEED and Greenstar respectively [41]. It was apparent from these assessments, that current GBRS underestimate the weighting of EE contributions.

The potential role of structural engineers in achieving reductions in environmental footprint of a building is commonly neglected due to the industry focus on OE [42]. A previous study suggested an initial over investment in EE was supported where the outcomes dictated BLC improvements in OE efficiencies [42]. It is accepted that there are justifiable motivations for this, however technologies are advancing. Zero Energy Buildings (ZEB) provides a new philosophy to enable stakeholders to contribute to the sustainable performance of structures. Zuo et al. [43] noted that technologies would not have to drastically improve to produce carbon-neutral buildings. ZEB have become increasingly common, with Zhedi [44], Marszal and Heiselberg [45] and Zuo et al. [43] all observing buildings with zero nett OE requirements (ZEBs). These studies also indicated 
that the incidence of ZEBs would increase [43-45]. Subsequently, continuation would result in the EE contribution of buildings being the sole influence of a BLC environmental energy performance. It has therefore been said that assessing the performance of ZEBs should appropriately incorporate the quantification of EE [46].

Whilst the significant contribution of OE in the BLC energy is noted, the literature suggests that increased involvement of structural engineers in decisions regarding sustainability would be desirable. It would not be implausible with the advent of ZEB for EE considerations to become the principal environmental performance consideration. In the short term, sustainability decisions would ideally be made by an interdisciplinary teams of professionals with structural engineers being a vital contributor [20]. To progress the enhancement of sustainability considerations in the building industry, a universal standard and mechanism are required. To date, no such instrument exists that appropriately considers all industry stakeholders [8, 20, 38].

The factors presented categorically reinforce the requirement for the improvement of the consideration of EE in the current building design and construction process as well as existing GBRS. It was anticipated that further developing an understanding of the existing GBRS and their contribution to the improvements in environmental performance of structures will contribute to the development of the supplementary tools required to improve buildings environmental performance. To successfully implement EE reducing initiatives in existing standards, acceptance by the industry is paramount. This research aims to verify the environmental consideration of structural systems in existing GBRS through an assessment and analysis of an industry perspective. As such, this study presents the results of a survey conducted amongst practicing engineers to further investigate potential challenges and issues from an alternate perspective. The survey aims to provide 
reference data for an industry perspective in relation to previous research conducted by the authors $[20,41]$.

\section{METHODOLOGY}

In order to obtain an understanding of the industry perspective being sought, a research survey was designed to provide to relevant industry stakeholders. These stakeholders were identified using requirements set out by the authors detailed below. Given the focus of this research, suitably qualified respondents had to be identified prior to the preparation of a potential list of participants. The survey was designed to assess the respondent's opinion in matters related to sustainability principles being incorporated into structural design. The survey was limited to practicing engineers and was designed to address prior experience, knowledge and or understanding of sustainable design and GBRS.

\subsection{Survey design}

To develop a profile of respondents, a number of background questions were formulated including:

- Geographical location of respondents

- Discipline of engineering including: structural (residential, multi-residential and commercial), civil, environmental, project management or academics.

- Respondents awareness of various GBRS

- Respondents involvement in projects involving various GBRS

Multiple questions were asked of respondents to gauge their understanding of these $\mathrm{OE}$ an EE factors as well as the GBRS included in this study. To investigate awareness of the importance of structural design in $\mathrm{SD}$, participants were asked to estimate the proportion 
of $\mathrm{EE}$ in a typical BLC. This question was later repeated for verification where respondents were asked to justify their estimate appropriately.

Through analysis, areas of interests were established involving aspects of sustainable structural engineering in general and more specifically structural design in GBRS. A number of statements (15) were prepared to cover these areas. Participants were given the opportunity to state their opinion by rating the statements from 1 (strongly disagree) to 5 (strongly agree). Space was provided for respondents to discuss areas of sustainable design not covered explicitly in the questionnaire.

\subsubsection{Sampling and Data Collection}

The sampling frame consisted of contact persons within appropriate engineering organisations identified by the research team. The research population has been defined as practicing engineers of civil engineering disciplines: structural, civil and environmental engineering and project management as well as academics in related fields employed in both the public and private sectors. Although geographically, the population was defined as relevant professionals Australia wide, due to restraints in the organisation of the survey, the majority of respondents were located in the South East Queensland region.

Survey responses were generated through a combination of hardcopy surveys and an online mechanism. Participants were invited to be involved through both email invitation and through discussion at Engineers Australia (EA) meetings. Online surveys were generated using the 'LimeSurvey V1.9x' online tool. Hardcopy surveys were distributed at identified engineering firms and at local EA meetings. 


\title{
2.2. Data Analysis
}

Relationships between responses were qualified and quantified using the Chi-square methodology. This approach compares the actual response data from a suspected relationship between a dependent and independent variable with a hypothetical probabilistic result if a relationship was absent [47]. The Chi square test is a statistical test applied to categorical data to determine how likely any observed differences between sets arose by chance [48]. This methodology considers the observed frequency of a combination of responses of an independent and a dependent variable in comparison with the expected frequency of a combination of responses of an independent and a dependent variable based on the distribution of the responses of the independent variable. The Chisquare test is the preferred tool for analysing (ordinarily) qualitative data [47]. In the analysis, when interrelation between two variables is suggested, the strength of the correlation is presented in terms of the Chi-square value $\left(\mathrm{x}^{2}\right)$ and the probability $(\mathrm{p})$ of the correlation.

\begin{abstract}
Although, as a result of the sampling methodology, statements regarding the response rate are difficult to make, the response was considered sufficient. At local Engineers Australia meetings, full response was achieved. Based on predictions of a theoretical maximum response, the actual response rate achieved was estimated at 54\% with a maximum possible responses being 98 respondents.
\end{abstract}

\section{RESULTS}

The following details the outcomes of the survey completed by the respondents as well as the importance of the findings in relation to the outcomes and comparison with previous research. 


\subsection{Response Demographic}

A total number of 53 responses were received from appropriately qualified professionals for the survey. Based on the survey sample size, a margin of error comparable to that determined (13.7\%) was expected and considered acceptable for the nature of this research [49].

Responses include those from practicing engineers in the public and private sector as well as academics with industry experience in relevant disciplines. The Engineering disciplines of respondents included: civil engineering (64.2\%), project management (39.6\%), environmental engineering (9.4\%) and structural engineering (40\%). A majority of respondents practice in multiple disciplines resulting in values greater than $100 \%$. Where individuals indicated they were active in multiple disciplines, all were included. The majority $(98.1 \%)$ of the respondents work on Queensland based engineering projects regularly. Other areas include Victoria (11.3\%), New South Wales (9.4\%), Northern Territories (5.7\%) and Western Australia and the ACT (2\% each). Consistent with the relevant engineering disciplines of individuals, respondents with experience in multiple states resulted in values greater than $100 \%$. Where individuals indicated they were experienced in multiple states, all were included. Given the uniformity of the industry, it was not determined that the strong representation of Queensland based professionals affected the ability of the survey to discuss engineering practice in Australia. However, caution was applied appropriately when discussing research findings. The demographic details of the respondents were summarised (Table 1).

The majority (81.1\%) of respondents were aware of the Greenstar GBRS (Table 2). BREEAM and LEED are internationally based GBRS, therefore their reduced awarness amongst respondents was expected. $35.9 \%$ of respondents indicated to have worked with 
as least one (1) GBRS. The category "other" for practical experience with GBRS includes all respondents that indicated to have worked with a GBRS but did not specify the actual GBRS. In accordance with outcomes of other demographic details, individuals provided multiple answers to this question. All options were included resulting in responses greater than $100 \%$.

The survey outcomes also identified that respondents from the strutural engineering discipline were more likely to be aware of GBRS than non-structural engineers $\left(x^{2}=4.04\right.$, $\mathrm{p}=95 \%$ ). $73 \%$ of respondents of a non-structural background knew of Greenstar compared to $95 \%$ of structural engineers.

\subsection{Embodied Energy and Operation Energy: Two improtant life cycle phases}

An important consideration in rating buildings on sustainability performance is the proportion of BLC energy considered EE and OE. The questionaire gauged the knowledge of respondents on this topic. Respondents were first asked to provide an estimate of the percentage EE in of total life cycle energy consumption. For the first estimate, respondents were not given answer options. A follow up question later in the survey for control purposes asked for the same estimate, however this time providing 5 answer options. Two questions were asked relating this topic for control purposes. These outcomes have been summarised (Table 3).

Analysis established that structural engineers are more likely to overestimate the contribution from $E E$ than other engineers $\left(1^{\text {st }}\right.$ estimate: $x^{2}=8.96, p=0.98,2^{\text {nd }}$ estimate: $x^{2}$ $=2.89, \mathrm{p}=0.75)$. Reasoning or awareness of a GBRS by respondents did not result in significant differences in estimates provided $\left(\mathrm{x}_{\max }^{2}=0.29, \mathrm{p}_{\max }=30 \%\right)$. 
Using the outcomes of previous research, the proportion of EE in a typical BLC was adopted as $18.6 \%$ [20]. When no answer options were provided, engineers are likely to overestimate the proportion of EE in total building life cycle energy (Figure 1). The respondents appeared to have an innate understanding of the contribution of these phases with the overall mean estimation provided by respondents of $28.4 \%$. No clear relationship was found between the correctness of the estimate and the awarenss of GBRS or engineering background. Respondents selection of " $20 \%$ Construction, $80 \%$ Operation" was the most frequently selected answer $(32.0 \%$ - Table 3$)$. The type of structures that respondents are involved in may have varying proportions of $\mathrm{OE}$ and $\mathrm{EE}$ that deviate from previously published results, leading the authors to apply caution when drawing conclusions.

The degree to which respondents underestimated or overestimated the proportion EE in both questions was displayed respectively. Respondents are likely to overestimate the proportion of EE when compared with the adopted value from previous research [20] (Figure $2 \mathrm{a}$ and $2 \mathrm{~b}$ ). As was established prior, Structural engineers were most likely to overestimate the significance of EE. $62.5 \%$ of respondents overestimated the proportion EE (Figure 2a) In comparison, 85\% of participating structural engineers provided an overestimation $\left(x^{2}=8.96, p=2 \%\right)$. It can also been seen by comparison (Figure $2 \mathrm{a}$ and Figure $2 b$ ) that when answer options were provided, respondents were more likely to estimate an accurate proportion of EE in a typical BLC $\left(x^{2}=7.79, p=99 \%\right)$.

Using the identified contribution of EE from previous research outcomes [20], the deviation by respondents from this value was presented using a cumulative frequency diagram (Figure 3). It can be seen that $10 \%$ of respondents provided an estimate of $0 \%$ 
error. A majority of respondents $(60 \%)$ were able to produce an estimate within $10 \%$ of the accurate value determined [20].

\subsection{Survey statement ratings of respondents}

Respondents were requested to give their opinion on a range of topics related to sustainable (structural) engineering by selectively rating 15 relevant statements. The rating scale ranged from 1 (strongly disagree) to 5 (strongly agree). Mean ratings of these responses for the respondents of the survey were presented including calculated corresponding standard deviation values and rankings (Table 4).

When analysing survey results, caution is required when interpreting these results (Table 4). Traditionally, mean values have a tendency to neglect scatter in data [50]. In accordance, mean ratings close to the median rating option (a value of 3) can be interpreted in a number of ways, including: 1) opinions by respondents are divided, 2) the majority of respondents were unsure or 3) the majority of respondents neither agreed nor disagreed. When studying the responses to individual questions, it was observed that the majority of respondents, eliminating these alternate interpretations, provided similar answers.

The responses to these statements by individuals have been summarised (Table 4). A number of observations were made from the analysis these responses with key results highlighted.

The majority of respondents agreed that structural engineers have an ethical obligation to consider environmental impact in their designs' with this response being the highest ranked outcome with $85 \%$ of respondents answering 4 or $5(\operatorname{Rank} 1$, Mean $=4.3 \pm 0.80)$. Significantly, $75 \%$ of respondents stated that economy is currently the main driving factor 
in structural design (Rank 2, Mean $=4 \pm 0.81$ ). Conversely, $41.2 \%$ of respondents disagreed with the statement "current legislation places too much emphasis on green building design”, whilst only $17.6 \%$ agreed (Rank 14 , Mean $=2.7 \pm 0.88)$ and respondents also belived current legislation is insufficient in relation to green building design (Rank 15 , Mean $=2.7 \pm 0.90)$.

\subsection{Participant Remarks}

Respondents were requested to provide comments on sustainable structural engineering. A discussion of these comments was provided. Numerous respondents stated that the use of sustainable materials would be important in the future with $30 \%$ remarking on this topic. From this cohort, $33 \%$ of those comments include or mention recyclability of- or the use of recycled building materials. Both (virgin) materials with a reduced energy footprint and recycled materials were listed in this regard. The use of timber was listed as a structural material on a number of occasions, however no opinion was provided on this material from the respondents. It was believed that ensuring both structural and economic benefits whilst delivering environmental sound performance is a challenge that engineers will continue to face. Convincing and educating clients and relevant stakeholders regarding the benefits of sustainable materials and design techniques were listed as another challenge, supported by the outcomes of the descriptive statement ratings. It was believed that clients lack the required understanding of available design options and their economic and environmental implications.

Respondents also specifically flagged the lack of support provided by legislation and or governing institutes who do not sufficiently provide the required incentive to achieve 
sustainable design. This was consistent with the outcomes of the descriptive statement ratings. However, respondents repeatedly raised the increase in complexity of the industry as a result of increased government involvement as a potential issue. Respondents identified government support as an important factor if GBRS are going to succeed in the future.

OE was listed as an important consideration by a number of respondents. Reducing operating cost through efficient building services and the thermal performance of a structure was discussed. In particular, respondents stated that under current GBRS, there exists a lack of requirement for maintenance of 'green fixtures'. 'Design performance' as well as 'actual performance' was also raised by respondents. Respondents identified the ongoing measurement of the as built performance of structures being lacking. It was believed this monitoring should be mandatory to ensure that these were consistent with the claimed performance of relevant systems during the design and GBRS assessment phase. It was suggested that additional proactive cooperation (specifically between architects and engineers) would assist in ensuring an optimal balance of EE and OE considerations.

Lastly the survey purposefully focused on the economic and environmental considerations of the sustainable development principles. Respondents repeatedly raised the importance of buildings meeting the requirements of the social considerations of sustainable development.

\subsection{Application of Research Outcomes}

After obtaining an industry perspective through the survey conducted, a comparison was performed with outcomes of previous research. Published contributions of EE and OE to a typical BLC were established from Miller and Doh [20]. In addition, a quantitative 
assessment was conducted into the allocation of points in the assessment criteria of three major GBRS (Greenstar, LEED and BREEAM), that could be attributed to the EE of a structure [41]. The outcomes of these studies were used to generate a figure enabling comparison of these various sources for consideration of the EE in a structural system (Figure 4).

Based on an assessment conducted in previous research, the three GBRS considered attribute $7 \%, 8 \%$ and $11 \%$ of points to the EE contribution of structures in relation to the assessment of environmental building performance [41] (Figure 4). In addition the average contribution of the EE phase of a BLC energy consumption was 18.6\% [20]. The survey results provided an additional estimation from the respondents. The average estimation of the contribution of EE to a structures BLC energy consumption from respondents was 28.4\%. These findings have been included for comparison with those of previous research (Figure 4).

\section{DISCUSSION}

A quantitative and qualitative survey was conducted. Fifty three (53) practicing engineers from a variety of backgrounds participated. The role of (structural) engineering in GBRS was specifically explored. It was found that the respondents exhibit a high awareness $(81.1 \%)$ of the Greenstar GBRS. This result was expected given the respondents being solely located in Australia. More than a third of participants have worked on projects that received a green building rating under some GBRS. The high incidence of awareness of a GBRS, as well as the rate of respondents with experience on a project involving some GBRS evidenced the suitability of the cohort of respondents. It was clear from the survey responses that the importance of and differentiation between EE and OE in reducing BLC 
energy consumption was understood. Previous research has identified that while there is variability in current estimates of EE and OEs contribution to a BLC energy consumption, $\approx 20 \%$ vs $80 \%$ respectively was presently accepted [20]. Respondents tended to overestimate rather than underestimate this percentage when compared to these previous outcomes (Table 3, Figure 1 and Figure 2).

The survey results suggest that respondents show an interest in the incorporation of sustainability principles into their design It was believed that ensuring environmental sustainability is an intrinsic component of the engineering profession (Rank 1, Mean $=4.3$ \pm 0.80 ). This was considered a positive outcome and consistent with previous guidelines issued by Engineers Australia (EA) [67]. EA actively encouraging the adoption of sustainable alternatives among its members [67]. Contrary to this however was the identification by respondents of the importance of economy in relation to matters of the current structural design process (Rank 2 , Mean $=4 \pm 0.81$ ). This was consistent with previous research which identified costs being presently considered the main driver in construction [29]. Overall, this result shows effort is required to shift the focus of the building industry to all aspects of SD.

It was also believed that government legislation should place more emphasis on this issue with responses on these questions being ranked 14 and 15 (Mean $=2.7 \pm 0.88$ and Mean $=$ $2.7 \pm 0.90$ ). This result was consistent with the expectations of the authors in accordance with previously published literature. Numerous authors have identified the need for legislative requirements being introduced to improve the environmental performance of the built environment $[1,20,32,68]$. The identification by $71.6 \%$ (Rank 3 , Mean $=3.8 \pm$ 0.88) of respondents believing tightening of future legislation on matters related to 
improve environmental performance of the built environment displays an optimistic tendency among respondents.

The effective use and reuse of structural materials was seen as the key consideration in improving environmental performance of buildings with $70 \%$ of respondents considering material selection the major consideration in environmentally sustainable structural design (Rank 4, Mean $=3.8 \pm 0.92)$. The identification of the importance of this issue by respondents was consistent with previously published research [69-74] yet the same importance was not assessed as being reflected appropriately in the inspected GBRS (Figure 4).

It was the belief of respondents that the key challenges to implementing sustainable structural design were:

- Maintaining costs at an acceptable level

- Convincing clients and other stakeholders of the benefits of sustainable design.

- Educating stakeholders on available design options

- Ensuring structural adequacy of materials with a reduced environmental footprint.

Based on the outcomes of the survey, respondents are committed to be actively involved in SD with this topic being the highest ranked outcome (Rank 1, Mean $=4.3 \pm 0.80$ ). It was previously observed however, that suitable mechanisms to be able to participate in sound environmental outcomes do not presently exist. Numerous authors have identified the requirement for a universal mechanism to be able to comprehensively assess the environmental performance of structures, however to date, no suitable mechanism exists $[8,20,38]$. The survey findings further evidence the urgent requirement for the development of such a mechanism with survey respondents presenting their agreement with the statement "It is likely that future legislation will put more pressure on structural 
engineers to consider the environmental performance of structural systems" (Rank 3, Mean $=3.8 \pm 0.88)$ and "Green building rating systems will play a greater role in structural design in the foreseeable future" (Rank 5, Mean = $3.8 \pm 1.00)$.

Previous research has importantly identified the consideration of EE by existing GBRS. This consideration is not disputed nor devalued by the outcomes of this research. Dixit et al. [8] and Ding [38] observed that existing GBRS considered EE through various evaluation criteria. Specifically material consumption categories and categories allowing for the use of locally available materials were raised as avenues for the consideration of EE [8]. However, no quantitative investigation into the proportion of points achievable and assigned to EE was conducted. Miller et al. [41] extended previous research by Miller and Doh [20] to systematically and quantitatively determine the proportion of points achievable and assigned to EE considerations under the Greenstar, BREEAM and LEED GBRS (Figure 4). The intention of these works was to consider whether the appropriate proportion of points attained under GBRS was consistent with the actual contribution of these $\mathrm{OE}$ and EE BLC phases. The outcomes determine that these proportions were not consistent and the survey results further support this finding (Figure 4). At present, the percentages of the GBRS attributable to the EE phase of structures BLC were determined by Miller et al. [41] as 7\%, $8 \%$ and $11 \%$ for Greenstar, LEED and BREEAM respectively. As previously mentioned, these results are compared to the $18.6 \%$ identified by Miller and Doh [20] and the findings of this survey $28.4 \%$ (Figure 4).

The importance of these outcomes are further evidenced by the consideration of the advent of ZEBs. With the identified underestimation of the points, which could be appropriately contributed to matters of EE in the GBRS considered, the divide between this and the actual contribution of EE will increase. If ZEBs achieve any outcome in the reduction of 
OE requirements, the outcome is a direct increase in EE contribution to total BLC energy consumption. With the incidence of ZEBs anticipated to escalate [43-45], the EE contributions discussed also increase in significance.

The focus of existing GBRS as well as the importance of OE requirements is accepted and promoted as an important consideration. The advent of these GBRS has played a vital role in the improvement of the building industry and this is not trivialised. The aspects through which existing criteria focus on the assessment of building performance are essential, with the authors attempting to provide supplementary information in regards to their further improvement. Dixit et al. [8], Ding [38] and Miller and Doh [20] note the requirement of further mechanisms in achieving improved environmental performance of structures and the existing assessment systems and the outcomes of this research provide further evidence.

\section{CONCLUSIONS AND RECOMMENDATIONS}

The outcomes of this research validate the findings of previous research conducted by the authors. By establishing an industry perspective on the factors presented here, the outcomes provide an additional verification method for comparison of and to assist with amendments to existing GBRS. Given the disparity between the contribution of EE and OE phases of the BLC and the points attributed to these in the current GBRS, the intention is to provide outcomes that close the gap between these estimations. Existing GBRS provide excellent mechanisms to promote and develop SD principles in the construction industry, however these need to be consistent with the present body of knowledge.

It is anticipated through highlighting these disparities, supplementary mechanisms would be investigated and developed to provide ancillary to existing GBRS. These mechanisms 
would accurately assess the environmental performance of structures through rigorous EE quantification given the ramifications on BLC energy phases as a result of the advent of ZEBs. Without highlighting the short falls present and developing mechanisms through which to improve them, the identified requirement for legislative and regulatory support will fail to gain momentum. It is the intention of the authors to develop such mechanisms with future research. 


\section{REFERENCES}

1. Hasegawa, T., Environmentally Sustainable Buildings - Challenges and Polocies. 2003, (OECD) Organisation for Economic Co-Operation and Development: Frane. p. 194.

2. Smith, P.F., Architecture in a Climate of Change. 2nd Edn ed. 2005, Oxford: Architectural Press.

3. Asif, M., Muneer, T., and Kelley, R., Life Cycle Assessment: A Case study of a dwelling home in Scotland. Building and Environment, 2007. 42: p. 1391-1394.

4. Citherlet, S. and Defaux, T., Energy and environmental comparison of three variants of a family house during its whole life span. Building and Environment, 2007. 42(2): p. 591-598.

5. Wood, A., Sustainability: A New High-Rise Vernacular? The Structural Design of Tall and Special Buildings, 2007. 16: p. 401-410.

6. Dimoudi, A. and Tompa, C., Energy and environmental indicators related to construction of office buildings. Resources, Conservation and Recycling, 2008. 53(1-2): p. 86-95.

7. Stephan, A., Crawford, R.H., and Myttenaere, K.d., Towards a more holistic approach to reducing the energ demand of dwellings. Procedia Engineering, 2011. 21: p. 1033-1041.

8. Dixit, M.K., Fernández-Solís, J.L., Lavy, S., and Culp, C.H., Need for an embodied energy measurement protocol for buildings: A review paper. Renewable and Sustainable Energy Reviews, 2012. 16(6): p. 3730-3743.

9. Langston, Y.L. and Langston, C.A., Reliability of building embodied energy modelling: an analysis of 30 Melbourne case studies. Construction Management and Economics, 2013. 26: p. 147-160.

10. Baek, C., Park, S.-H., Suzuki, M., and Lee, S.-H., Life cycle carbon dioxide assessment tool for buildings in the schematic design phase. Energy and Buildings, 2013. 61: p. 275-287.

11. Lele, S.M., Sustainable Development: A Critical Review. World Develoment, 1991. 19(6): p. 607621.

12. Mebratu, D., Sustainability and Sustainable Development: Historical and Conceptual Review. Environmental Impact Assessment, 1998. 18: p. 493-520.

13. Pérez-Lombard, L., Ortiz, J., and Pout, C., A review on buildings energy consumption information. Energy and Buildings, 2008. 40(3): p. 394-398.

14. Environmental Protection Agency (EPA), Buildings and their impact on the Environment: A Statistical Summary. 2009, Environmental Protection Agency: Washington.

15. Chau, C.K., Hui, W.K., Ng, W.Y., and Powell, G., Assessment of CO2 emissions reduction in highrise concrete office buildings using different material use options. Resources, Conservation and Recycling, 2012. 61: p. 22-34.

16. Australian Bureau of Statistics (ABS), Australia's Environment: Issues and Trends CAT No. 4613.0. 2010: Canberra. 
17. Frey, P.J., Measuring Up: The Performance of Historic Buildings Under the Leed-NC Green

Building Rating System, in Historic Preservation. 2007, University of Pannsylvania: Pennsylvania.

18. Australian Bureau of Statistics (ABS). 1370.0 - Measures of Australia's Progress. 201017 March, 2012; Available from: http://www.abs.gov.au/ausstats/abs@.nsf/Lookup/by

Subject/1370.0 2010 Chapter Population projections (3.4).

19. Kates, R., Population and Consumption: What We Know, What We Need to Know. Environment, 2000. 42(3): p. 10-19.

20. Miller, D. and Doh, J.-H., Incorporating sustainable development principles into building design: a review from a structural perspective including case study. The Structural Design of Tall and Special Buildings, 2014.

21. Walker-Morison, A., Grant, T., and McAlister, S., The Environmental Impact of Building Materials. Environment Design Guide, 2007. PRO 7.

22. Lippiatt, B.C., Selecting Cost Effective Green Building Products: BEES Approach. Journal of Construction Engineering and Management, 1999. 125: p. 448-455.

23. Chong, W.K., Kumar, S., Haas, C.T., Beheiry, S.M.A., Coplen, L., and Oey, M., Understanding and Interpreting Baseline Perceptions of Sustainability in Construction among Civil Engineers in the United States. Journal of Management in Engineering, 2009. 25(3): p. 143-154.

24. Flower, D.J.M. and Sanjayan, J.G., Green house gas emissions due to concrete manufacture. The International Journal of Life Cycle Assessment, 2007. 12(5): p. 282-288.

25. Oh, D.-Y., Noguchi, T., Kitagaki, R., and Park, W.-J., CO2 emission reduction by reuse of building material waste in the Japanese cement industry. Renewable and Sustainable Energy Reviews, 2014. 38: p. 796-810.

26. Miller, D., Doh, J.-H., and Guan, H. Environmentally Efficient and Sustainable Design Methodology of Concrete Residential and Office Buildings: A Review. in The 2011 International Conference on Advances in Structural Engineering and Mechanics. 2011. Seoul, Korea.

27. European Union (EU), An Agenda For Sustainable Construction in Europe. 2001: Brussels. p. 65.

28. Cement, Concrete \& Aggregates Australia, (CCAA) Sustainable Concrete Buildings. 2010, Cement, Concrete \& Aggregates Australia: Sydney. p. 8.

29. Adams, W.M., The Future of Sustainability: Re-thinking Environment and Development in the Twenty-first Century. 2006, (IUCN) The World Conservation Union.

30. Xundi, D., Liyin, S., Saixing, Z., Jose Jorge, O., and Xiaoling, Z., Relationship between energy consumption and economic development in construction industry. Journal of Engineering, Design and Technology, 2010. 8(3): p. 257-273.

31. Turner, R.K., Sustainability auditing and assessment challenges. Building Research \& Information, 2006. 34(3): p. 197-200.

32. Intergovernmental Panel on Climate Change (IPCC), GEO 4: Environment for Development. 2007, United Nations Environment Programme (UNEP): Malta. 
33. Fowler, K.M. and Ranch, E.M., Sustainable Building Rating Systems Summary. 2006, Pacific Northwest National Laboratory: Washington.

34. Bilec, M., Ries, R., and Matthews, H.S., Sustainable Development and Green Design - Who Is Leading the Green Initiative? Joural of Professional Issues in Engineering Education and Practice, 2007: p. 265-269.

35. Clark, D., Incentives for Sustainable Buildings in Australia - A Designer's Perspective. n.d, Sinclair Knight Merz.

36. Deane, M., The builder's role in delivering sustainable tall buildings. The Structural Design of Tall and Special Buildings, 2008. 17(5): p. 869-880.

37. Department of the Environment and Water Resources (DEWR), ESD Design Guide: Office and Public Buildings 3rd Edition. 2007, Commonwealth of Australia: Canberra. p. 74.

38. Ding, G.K., Sustainable construction--the role of environmental assessment tools. J Environ Manage, 2008. 86(3): p. 451-64.

39. Goggins, J., Keane, T., and Kelly, A., The assessment of embodied energy in typical reinforced concrete building structures in Ireland. Energy and Buildings, 2010. 42(5): p. 735-744.

40. Dixit, M.K., Fernández-Solís, J.L., Lavy, S., and Culp, C.H., Identification of parameters for embodied energy measurement: A literature review. Energy and Buildings, 2010. 42(8): p. 12381247.

41. Miller, D., Doh, J.-H., Lima, M.M., and Oers, N.v., Embodied Energy Assessment of the Structural System in Concrete Buildings: A Case Study on 7 South East Queensland Structures, in 23rd Australasian Conference on the Mechanics of Structures and Materials ACMSM23, S.T. Smith, Editor. 2014: Byron Bay.

42. Ramesh, T., Prakash, R., and Shukla, K.K., Life cycle energy analysis of buildings: An overview. Energy and Buildings, 2010. 42(10): p. 1592-1600.

43. Zuo, J., Read, B., Pullen, S., and Shi, Q., Achieving carbon neutrality in commercial building developments - Perceptions of the construction industry. Habitat International, 2012. 36(2): p. 278286.

44. Zahedi, A., Australian Renewable Energy Progress. Renewable and Sustainable Energy Reviews, 2010. 14: p. 2208-2213.

45. Marszal, A.J. and Heiselberg, P., Life cycle cost analysis of a multi-storey residential Net Zero Energy Building in Denmark. Energy, 2011. 36(9): p. 5600-5609.

46. Butera, F.M., Zero-energy buildings: the challenges. Advances in Building Energy Research, 2013. 7(1): p. 51-65.

47. Kooiker, R., Broekhoff, M., and Stumpel, H., Marktonderzoek (Market Research). 2007, Groingen: Wolters-Nordhoff. 
48. Xue, P., Mak, C.M., and Cheung, H.D., The effects of daylighting and human behavior on luminous comfort in residential buildings: A questionnaire survey. Building and Environment, 2014. 81: p. 51-59.

49. American Association for Public Opinion Research (AAPOR). Margin of Sampling Error. 2007 [cited 2014 14th November]; Available from: http://www.aapor.org/Margin_of_Sampling_Error1.htm - .VHMva4uK31g.

50. Byrne, D., Interpreting Duantitative Data. 2002, London: SAGE Publications Ltd.

51. Cole, R.J. and Kernan, P.C., Life-Cycle Energy Use in Office Buildings. Building and Environment, 1996. 31(4): p. 307-317.

52. Adalberth, K., Energy use during the Life Cycle of Buildings: a Method. Building and Environment, 1997. 32(4): p. 317-320.

53. Suzuki, M. and Oka, T., Estimation of life cycle energy consumption and CO2 emission of office buildings in Japan. Energy and Buildings, 1998. 28: p. 33-41.

54. Cole, R.J., Energy and Greenhouse Gas Emissions Associated with the Construction of Alternative Structural Systems. Building and Environment, 1999. 34: p. 335-348.

55. Fay, R., Treloar, G., and Iyer-Raniga, U., Life-cycle energy analysis of buildings: a case study. Building Research \& Information, 2000. 28(1): p. 31-41.

56. Pullen, S., Energy Assessment of Institutional Buildings, in Proceedings of Annual Conference of the Australia \& New Zealand Architectural Science Association (ANZAScA). 2000, The University of Adelaide: South Australia.

57. Yohanis, Y.G. and Norton, B., Life-cycle Operational and Embodied Energy for a Generic Single Storey Office Building in the UK. Energy, 2002. 27: p. 77-92.

58. Hes, D. and Bates, M., Concrete and Sustainability - Supporting Environmentally Responsible Decision Making. Environment Design Guide, 2003. PRO 31.

59. Guggemos, A.A. and Horvath, A., Comparison of Environmental Effects of Steel and Concrete Framed Buildings. Journal of Infrastructure Systems, 2005. 11(2): p. 93-101.

60. Yohanis, Y.G. and Norton, B., Including embodied energy considerations at the conceptual stage of building design. Procedings of the Institution of Mechanical Engineers, 2006. 220: p. 271-288.

61. Kofoworola, O.F. and Gheewala, S.H., Life Cycle Energy Assessment of a typical office building in Thailand. Energy and Buildings, 2009. 41: p. 1076-1083.

62. Sharma, A., Saxena, A., Sethi, M., Shree, V., and Varun, Life cycle assessment of buildings: A review. Renewable and Sustainable Energy Reviews, 2011. 15(1): p. 871-875.

63. Jiao, Y., Lloyd, C.R., and Wakes, S.J., The relationship between total embodied energy and const of commercial buildings. Energy and Buildings, 2012. 52: p. 20-27. 
64. Wu, H.J., Yuan, Z.W., Zhang, L., and Bi, J., Life cycle energy consumption and CO2 emission of an office building in China. The International Journal of Life Cycle Assessment, 2011. 17(2): p. 105118.

65. Kua, H.W. and Wong, C.L., Analysing the life cycle greenhouse gas emission and energy consumption of a multi-storied commercial building in Singapore from an extended system boundary perspective. Energy and Buildings, 2012. 51: p. 6-14.

66. Cabeza, L.F., Barreneche, C., Miro, L., Morera, J.M., Bartoli, E., and Fernandez, A.I., Low Carbon and low embodied energy materials in buildings. Renewable and Sustainable Energy Reviews, 2013. 23: p. 536-542.

67. Engineers Australia (EA), Policy Statement - Sustainable Environmental Practice, Engineers Australia National Council, Editor. 2003, Engineers Australia: Sydney.

68. Hood, D., Implementing Energy Efficiency and ESD from a Development Perspective. Environment Design Guide, 2004. GEN 60.

69. Vandecasteele, C. and van der Sloot, H., Sustainable management of waste and recycled materials in construction. Waste Manag, 2011. 31(2): p. 199-200.

70. Sieffert, Y., Huygen, J.M., and Daudon, D., Sustainable construction with repurposed materials in the context of a civil engineering-architecture collaboration. Journal of Cleaner Production, 2014. 67: p. 125-138.

71. Kelly, E. and McCarthy, T.J., Sustainable Structural Design: Conceptual Design of Adaptable Commercial Buildings, in Australasian Structural Engineering Conference (ASEC), E. Gad and B. Wong, Editors. 2008: Melbourne, Australia. p. 9.

72. Yeo, D. and Gabbai, R.D., Sustainable design of reinforced concrete structures through embodied energy optimization. Energy and Buildings, 2011. 43(2011): p. 2028-2033.

73. Omar, W.M.S.W., Doh, J.-H., Panuwatwanich, K., and Miller, D., Assessment of the embodied carbon in precast concrete wall panels using a hybrid life cycle assessment approach in Malaysia. Sustainable Cities and Society, 2013. 10: p. 1-11.

74. Myers, F., Fuller, R., and Crawford, R.H., The potential to reduce the embodied energy in construction through the use of renewable materials, in ASA 2012: Building on knowledge, theory and practice: Proceedings of the 46th Annual Conference of the Architectural Science Association. 2012, Architectural Science Association: Gold Coast, Queensland. p. 1-8. 
Table 1: Survey response demographics

\begin{tabular}{|c|c|c|c|c|c|c|}
\hline State of Practice* & $\begin{array}{c}\text { Number of } \\
\text { Respondents }\end{array}$ & $\begin{array}{c}\% \text { of } \\
\text { Respondents** }\end{array}$ & \multicolumn{2}{|c|}{$\begin{array}{c}\text { Engineering } \\
\text { Discipline }\end{array}$} & $\begin{array}{c}\text { Number of } \\
\text { Respondents }\end{array}$ & $\begin{array}{c}\% \text { of } \\
\text { Respondents** }\end{array}$ \\
\hline New South Wales & 5 & $9.4 \%$ & \multicolumn{2}{|c|}{ Civil } & 34 & $64.2 \%$ \\
\hline Queensland & 52 & $98.1 \%$ & \multicolumn{2}{|c|}{ Environmental } & 5 & $9.4 \%$ \\
\hline South Australia & 1 & $1.9 \%$ & \multicolumn{2}{|c|}{ Project Management } & 21 & $39.6 \%$ \\
\hline Tasmania & 1 & $1.9 \%$ & \multirow[t]{3}{*}{ Structural } & - Residential & 14 & $26.4 \%$ \\
\hline Victoria & 6 & $11.3 \%$ & & - Commercial & 18 & $34.0 \%$ \\
\hline Western Australia & 1 & $1.8 \%$ & & - Multi-residential & 13 & $24.5 \%$ \\
\hline ACT & 1 & $1.8 \%$ & \multirow{2}{*}{\multicolumn{2}{|c|}{ Other }} & 10 & $18.9 \%$ \\
\hline Northern Territories & 3 & $5.7 \%$ & & & & \\
\hline
\end{tabular}

Table 2: Respondent experience with GBRS: awareness and working experience

\begin{tabular}{|c|c|c|}
\hline Rating System & Number of Respondents & $\%$ of Respondents** \\
\hline \multicolumn{3}{|c|}{ Awareness of Rating System } \\
\hline Green Star & 43 & $81.1 \%$ \\
\hline BREEAM & 10 & $18.9 \%$ \\
\hline LEED & 10 & $18.9 \%$ \\
\hline *Other & 3 & $5.7 \%$ \\
\hline \multicolumn{3}{|c|}{ Working experience Rating System } \\
\hline Green Star & 2 & $3.8 \%$ \\
\hline BREEAM & 1 & $1.9 \%$ \\
\hline LEED & 1 & $1.9 \%$ \\
\hline *Other & 15 & $28.3 \%$ \\
\hline
\end{tabular}

* Other includes systems not explicitly specified in the survey

** Includes multiple responses from individuals $(>100 \%)$

Table 3: Summary of estimates for the contribution of EE and OE of BLC energy consumption

\begin{tabular}{|c|c|c|c|c|c|c|c|c|}
\hline \multirow[t]{2}{*}{ Result } & \multicolumn{2}{|c|}{ Total Estimates } & \multicolumn{2}{|c|}{$\begin{array}{c}\text { Well-reasoned } \\
\text { Estimates* }\end{array}$} & \multicolumn{2}{|c|}{$\begin{array}{c}\text { Estimates by } \\
\text { Structural Engineers }\end{array}$} & \multicolumn{2}{|c|}{$\begin{array}{c}\text { Estimates by Respondents } \\
\text { aware of a GBRS }\end{array}$} \\
\hline & Number $^{\#}$ & $\%$ & Number & $\%$ & Number & $\%$ & Number & $\%$ \\
\hline \multicolumn{9}{|c|}{ 1st Estimate (no answer options provided in the survey) } \\
\hline Underestimated & 13 & $27.1 \%$ & 9 & $27.3 \%$ & 1 & $5.0 \%$ & 11 & $26.8 \%$ \\
\hline Correct Estimation $* *$ & 5 & $10.4 \%$ & 4 & $12.1 \%$ & 2 & $10.0 \%$ & 5 & $12.2 \%$ \\
\hline Overestimated & 30 & $62.5 \%$ & 20 & $60.6 \%$ & 17 & $85.0 \%$ & 25 & $61.0 \%$ \\
\hline Total & 48 & $100 \%$ & 33 & $100 \%$ & 20 & $100 \%$ & 41 & $100.0 \%$ \\
\hline \multicolumn{9}{|c|}{ 2nd Estimate (answer options provided in the survey) } \\
\hline Underestimated & 14 & $28.0 \%$ & 9 & $28.1 \%$ & 3 & $15.0 \%$ & 11 & $26.8 \%$ \\
\hline Correct Estimation** & 16 & $32.0 \%$ & 11 & $34.4 \%$ & 8 & $40.0 \%$ & 13 & $31.7 \%$ \\
\hline Overestimated & 20 & $40.0 \%$ & 12 & $37.5 \%$ & 9 & $45.0 \%$ & 17 & $41.5 \%$ \\
\hline Total & 50 & $100 \%$ & 32 & $100.0 \%$ & 20 & $100 \%$ & 41 & $100.0 \%$ \\
\hline
\end{tabular}

*Well-reasoned was defined as based on a qualitative and quantitative method or based on prior knowledge or experience

**Correct Estimate was considered $20 \%$ EE without any error allowed

${ }^{\#}$ Some individuals did not respond to all questions (Total $\neq 53$ ) 
Table 4: Ratings provided on 5 point scale statements of the completed survey

\begin{tabular}{|c|c|c|c|c|c|c|c|c|c|}
\hline \multirow[t]{2}{*}{ Statement } & \multicolumn{3}{|c|}{$\begin{array}{l}\text { Strongly } \\
\text { Disagree }\end{array}$} & \multicolumn{2}{|c|}{$\begin{array}{l}\text { Strongly } \\
\text { Agree }\end{array}$} & \multirow{2}{*}{$\begin{array}{c}\text { Total } \\
\text { Responses }\end{array}$} & \multirow[t]{2}{*}{ Mean } & \multirow{2}{*}{$\begin{array}{l}\text { Standard } \\
\text { Deviation }\end{array}$} & \multirow[t]{2}{*}{ Rank } \\
\hline & 1 & 2 & 3 & 4 & 5 & & & & \\
\hline $\begin{array}{l}\text { Structural engineers have an ethical obligation to } \\
\text { consider environmental impact in their designs. }\end{array}$ & 0 & 2 & 6 & 21 & 24 & 53 & 4.3 & 0.80 & 1 \\
\hline $\begin{array}{l}\text { Environmental performance is a major consideration on } \\
\text { most projects I have been involved in. }\end{array}$ & 3 & 17 & 17 & 10 & 3 & 50 & 2.9 & 1.00 & 12 \\
\hline $\begin{array}{l}\text { It is likely that future legislation will put more pressure } \\
\text { on structural engineers to consider the environmental } \\
\text { performance of structural systems. }\end{array}$ & 1 & 4 & 10 & 29 & 9 & 53 & 3.8 & 0.88 & 3 \\
\hline $\begin{array}{l}\text { Engineers have little control over the environmental } \\
\text { performance of a building compared to clients and } \\
\text { architects. }\end{array}$ & 2 & 17 & 14 & 12 & 8 & 53 & 3.1 & 1.13 & 10 \\
\hline $\begin{array}{c}\text { Economy is currently the main driving factor in } \\
\text { structural design. }\end{array}$ & 0 & 2 & 11 & 24 & 16 & 53 & 4 & 0.81 & 2 \\
\hline $\begin{array}{l}\text { Green building rating systems will play a greater role in } \\
\text { structural design in the foreseeable future. }\end{array}$ & 2 & 3 & 11 & 23 & 14 & 53 & 3.8 & 1.00 & 5 \\
\hline $\begin{array}{l}\text { Increasingly, clients express their demands for } \\
\text { environmental sustainable design. }\end{array}$ & 0 & 9 & 17 & 18 & 8 & 52 & 3.5 & 0.95 & 8 \\
\hline $\begin{array}{l}\text { Material selection is the major consideration of structural } \\
\text { engineers when designing for environmental } \\
\text { performance. }\end{array}$ & 1 & 4 & 11 & 26 & 11 & 53 & 3.8 & 0.92 & 4 \\
\hline $\begin{array}{l}\text { Current legislation places sufficient emphasis on green } \\
\text { building design. }\end{array}$ & 4 & 19 & 17 & 11 & 0 & 51 & 2.7 & 0.90 & 15 \\
\hline $\begin{array}{l}\text { Green building rating systems underestimate structural } \\
\text { design considerations. }\end{array}$ & 0 & 6 & 31 & 7 & 6 & 50 & 3.3 & 0.82 & 9 \\
\hline $\begin{array}{l}\text { Criteria used by rating systems cover all aspects of } \\
\text { building construction and operation appropriately. }\end{array}$ & 3 & 12 & 27 & 9 & 0 & 51 & 2.8 & 0.78 & 13 \\
\hline $\begin{array}{c}\text { Current legislation places too much emphasis on 'green' } \\
\text { building design. }\end{array}$ & 5 & 16 & 21 & 9 & 0 & 51 & 2.7 & 0.88 & 14 \\
\hline $\begin{array}{l}\text { Construction energy should be equally considered by } \\
\text { green building rating systems as operational energy. }\end{array}$ & 0 & 7 & 14 & 23 & 9 & 53 & 3.6 & 0.91 & 7 \\
\hline $\begin{array}{l}\text { Structural materials selection is a more important } \\
\text { consideration in reducing construction energy than non- } \\
\text { structural materials selection. }\end{array}$ & 2 & 14 & 23 & 8 & 6 & 53 & 3 & 1.01 & 11 \\
\hline $\begin{array}{l}\text { My company actively promotes solutions for clients that } \\
\text { we believe are sustainable alternatives. }\end{array}$ & 2 & 2 & 15 & 23 & 5 & 47 & 3.6 & 0.89 & 6 \\
\hline
\end{tabular}




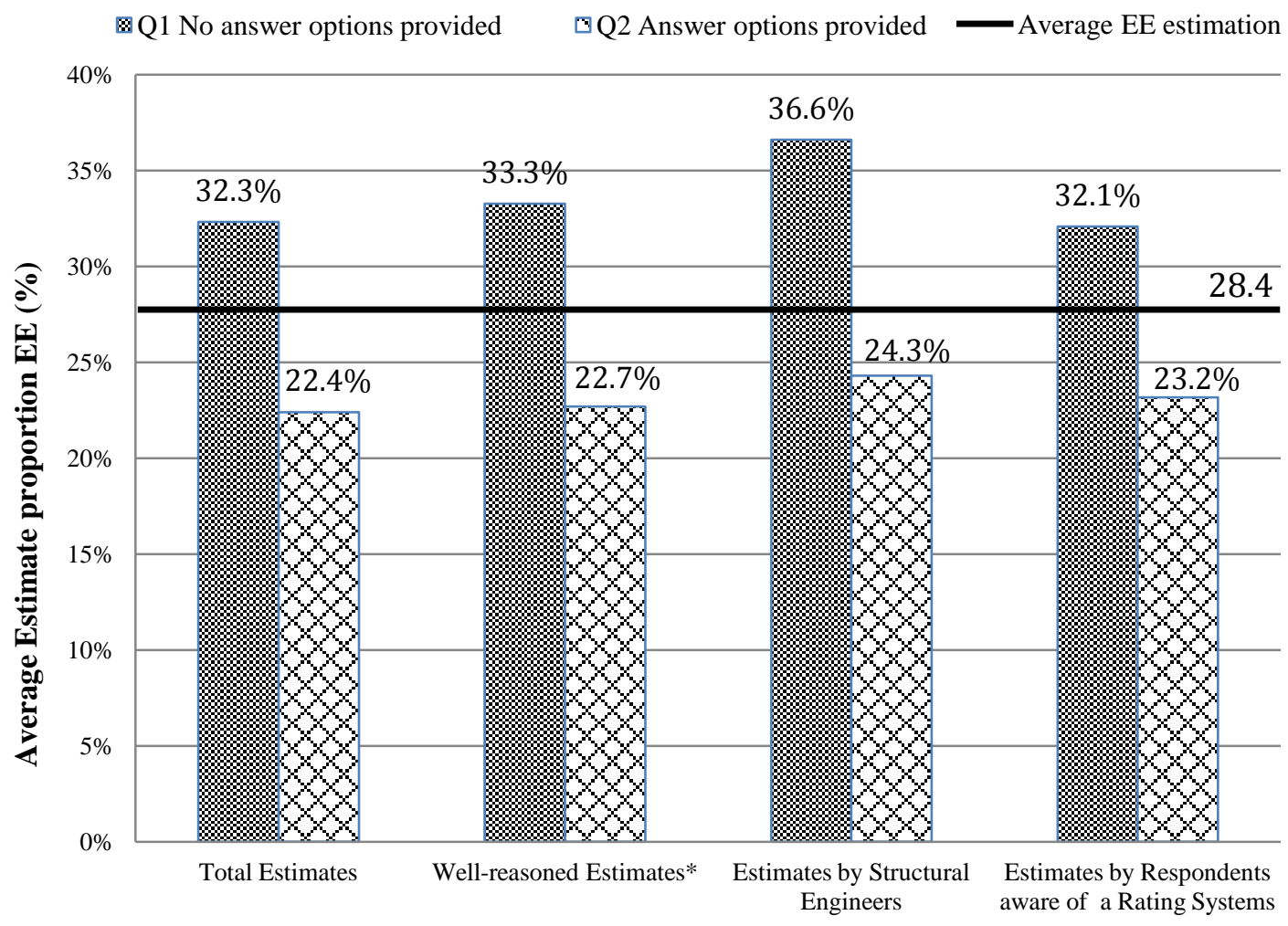

Figure 1: Survey average estimate of the percentage of EE in a tyical BLC. *Well-reasoned estimates are considered estimates where respondents provided a numerical or qualitative reasoning for the estimate or gave an answer based on prior knowledge or experience

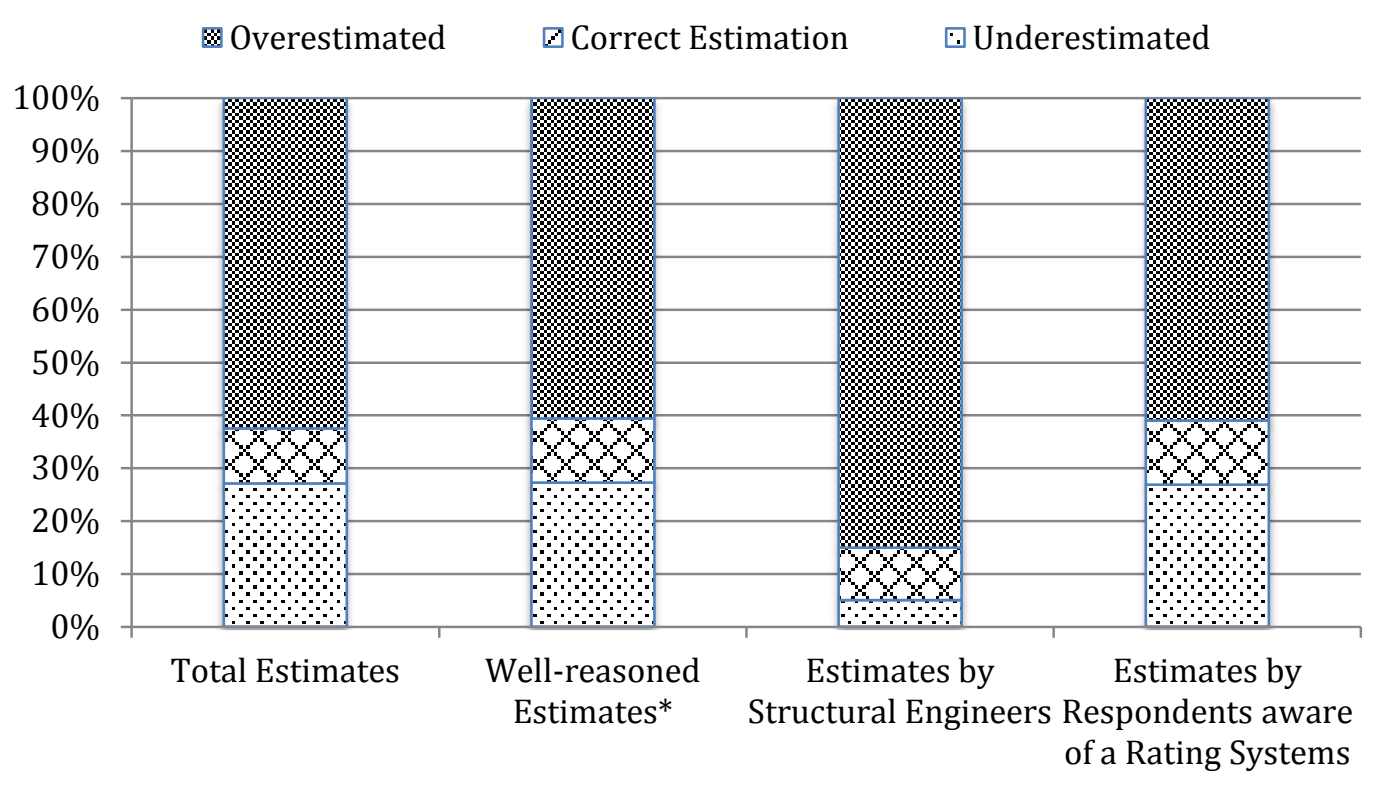

(a) 


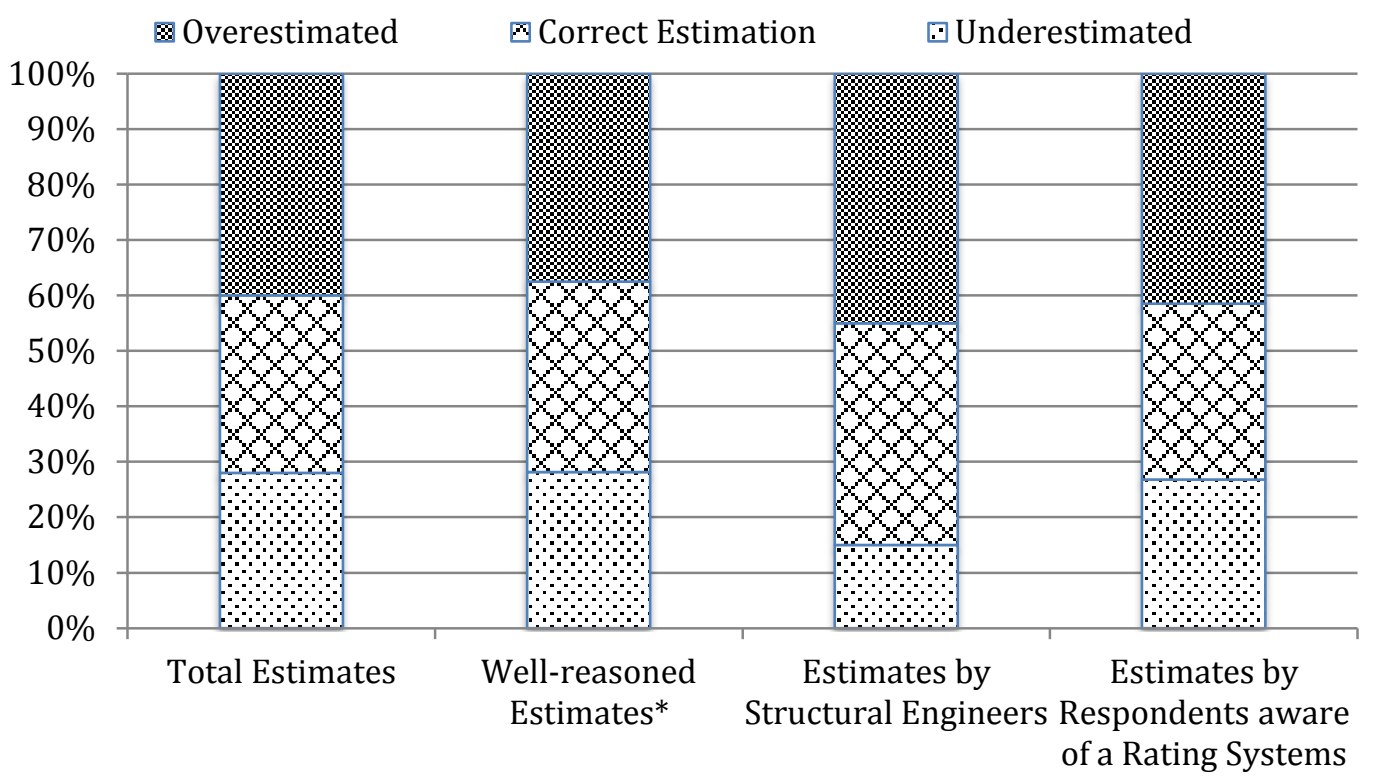

(b)

Figure 2: Accuracy of estimates of the proportion of EE in total building life cycle energy. (a) No answer options were provided in the survey. (b) Answer options were provided in the survey.

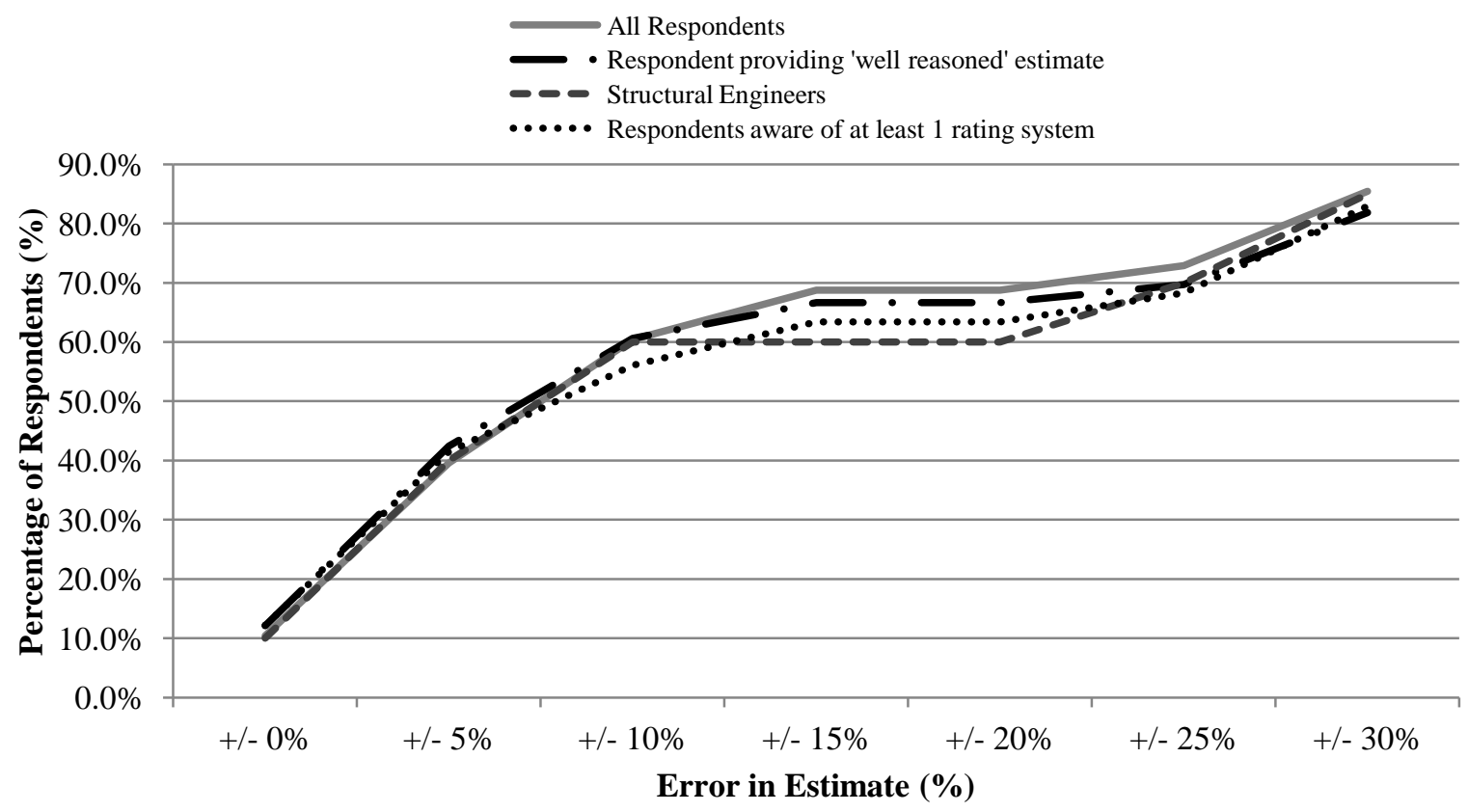

Figure 3: Cumulative frequency of the error in estimating the proportion of EE in total BLC energy by respondent background. 


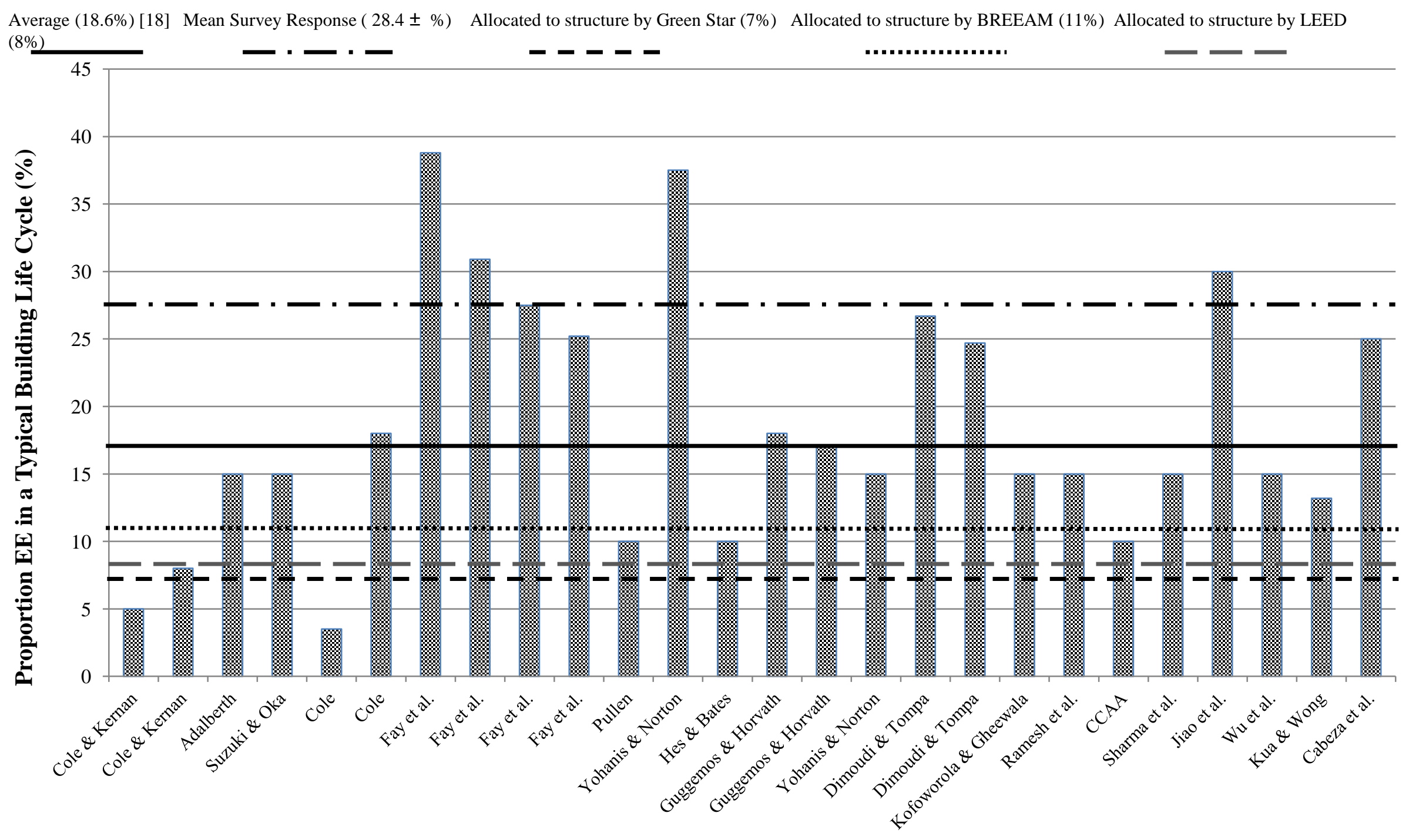

Figure 4: EE consideration in structures according to various assessment processors (Extended from Miller et al. [41] 